\title{
A formação de professores na rede estadual paulista entre 1983 e 2006: uma análise crítica
}

\author{
Bruno Gonçalves Lippi \\ Universidade de São Paulo, São Paulo, SP - Brasil \\ bruno.lippi@uol.com.br \\ Marcos Garcia Neira \\ Universidade de São Paulo, São Paulo, SP - Brasil \\ mgneira@usp.br
}

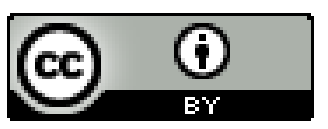

Educação: teoria e prática, Rio Claro, SP, Brasil - elSSN: 1981-8106

Está licenciada sob Licença Creative Common

\section{Resumo}

Neste artigo, foram analisadas as políticas de formação contínua de professores da rede estadual paulista entre 1983 e 2006. Esse recorte histórico justifica-se pela retomada de governos eleitos democraticamente e pela suspeita de que as ações formativas, implementadas nesse período, seguem influenciando as iniciativas atuais. As propostas de formação docente, por mais que sejam isoladas, inserem-se no bojo de uma política maior, ou seja, são dotadas de uma determinada intencionalidade. A compilação e análise crítica dos estudos que se debruçaram sobre as políticas de formação contínua de professores, implementadas pela Secretaria Estadual da Educação de São Paulo (SEE/SP), permitiram a divisão do período em dois ciclos. O primeiro (1983-1994) foi marcado pela busca de alternativas para democratização e descentralização do processo de formação. E o segundo (1995-2006) foi caracterizado pela prevalência de políticas alinhadas ao ideário neoliberal, consubstanciadas na pulverização de iniciativas e em convênios e parcerias com instituições diversas.

Palavras-chave: Política Educacional. Neoliberalismo. Formação Contínua.

\section{Teachers training in the educational web of São Paulo State: between 1983 and 2006: a critical analysis}


In this article it was examined the policies of teachers training in the state of São Paulo between 1983 and 2006. The option for this historical view is justified by the return of democratically elected governments and also by the suspicion that the training activities implemented during this period continued to influence substantially the current initiatives. The proposals for teacher training, even if they are isolated, fall in the middle of a larger policy, that means, they are having a specific intention. The compilation and critical analysis of studies that have focused on the service teacher training policies implemented by the State department of Education of São Paulo (SEE / SP) allowed the division of period two cycles. The first (1983-1994) was marked by the search for alternatives to break the paradigms imposed by the previous dictatorial governments, there have been marked by attempts to decentralize the process. And second (1995-2006) was characterized by the frequency of policies aligned with the neoliberal ideas, conjugated in the spreading of initiatives and agreements and partnerships with various institutions.

Keywords: Educational Policy. Neoliberalism. Training.

\section{Introdução}

A partir de 2007, observa-se certa inflexão das políticas educacionais da Secretaria da Educação do Estado de São Paulo (SEE/SP) à atual hegemonia do perfil neoliberal nas sociedades democráticas ocidentais. Avaliações padronizadas de alunos e professores, comparação de desempenho de escolas, remuneração por resultados e implantação de currículos centralizados são as marcas mais visíveis desse processo. As ações formativas implementadas, evidentemente, são apenas mais um dos elementos desse conjunto.

Iniciativas governamentais não emergem de ideias abstratas, são sempre circunstanciais. Buscam subsídios nos discursos, experiências e nas políticas anteriores ou circulantes. Aceita essa premissa, poder-se-á afirmar que os contornos atuais das políticas de formação contínua de professores da rede estadual serão mais bem compreendidos caso se obtenha um conhecimento mais profundo da sua trajetória.

Tal raciocínio levou-nos a compilar e analisar os estudos que abarcaram a problemática no período de 1983 a 2006, movidos pela intenção de identificar os fatores que delinearam os procedimentos adotados pela SEE/SP e as concepções que fundamentaram suas políticas formativas.

Procurando compreender as relações de força que influenciaram a inovação, interrupção ou continuidade nas políticas de formação contínua, as análises permitiram dividir o período histórico em dois ciclos. O primeiro, de 1983 a 1994, foi marcado pela pulverização de tentativas de romper com os paradigmas impostos pelos governos ditatoriais antecedentes. E o segundo, entre 1995 e 2006, caracterizou-se pela prevalência 
de políticas alinhadas ao ideário neoliberal. Os resultados de nossas análises contrariam qualquer discurso de mudança de rumos ou direções. Inversamente, sobram razões para afirmar a existência de um continuum nas ações formativas. As evidências indicam que a centralização das decisões, as iniciativas episódicas, a ausência de canais de diálogo com os profissionais da educação e a falta de criticidade com relação à tarefa educacional, há muito permeiam a política estadual de formação de professores.

\section{Ciclo I (1983 a 1994): Continuidade ou descontinuidade, transformação ou manutenção?}

Do ponto de vista político, o período marca o retorno ao estado democrático. Os novos ares proporcionados pelo movimento das Diretas Já, pelo debate em torno de uma nova constituição e pela revisão das leis vigentes durante a ditadura influenciaram as políticas educacionais. Sendo o primeiro governo eleito pós-ditadura, a gestão Franco Montoro (1983-1987) privilegiou a descentralização administrativa e a participação popular nas decisões governamentais (MARTINS, 1998). Na área educacional, entendia-se por democratização do ensino, a universalização do acesso e instauração de mecanismos de participação popular na gestão, dentre eles, o Conselho de Escola.

Administrativamente, a SEE/SP possui uma estrutura hierárquica piramidal, na qual as decisões tomadas no topo lançam exigências às instâncias inferiores e assim, sucessivamente, até chegar às escolas. A Coordenadoria de Estudos e Normas Pedagógicas (CENP), responsável pela formação docente; a Fundação para o Desenvolvimento do Ensino (FDE), responsável pela aquisição de materiais, reformas nas escolas, entre outras atribuições; e o Departamento de Recursos Humanos (DRHU), responsável pela contratação e carreira dos funcionários e docentes vinculados à pasta, foram os órgãos que, no período, interferiram na política de formação contínua. Com amplo destaque, a CENP concentrou a elaboração, execução e normatização das propostas curriculares para o Estado; o desenvolvimento de estudos para produção e aperfeiçoamento de materiais pedagógicos e metodologias de ensino; e o trabalho de qualificação e requalificação docente, técnicopedagógica e administrativa (SÃO PAULO, 2008a).

A hierarquização influencia todas as ações do sistema educacional, inclusive as formativas, pois, a partir desse modelo, a formação contínua tende a se tornar estratégia de 
convencimento das políticas centrais, visto que sem a sedução dos executores, no caso os professores, aquelas não se consolidam (FUSARI, 1988). Sendo assim, não deixa de ser paradoxal a intenção de democratizar as decisões da administração pública uma vez que as estruturas estão contaminadas pelo autoritarismo. Tome-se por sintoma a instauração de Conselhos de Escola, de cunho deliberativo, em uma máquina movida à base de resoluções normativas fundadas no mando e obediência.

Almejando combater a evasão, repetência e fracasso escolar, em 1984 foi implantado o Ciclo Básico. Extinguiu-se a reprovação entre os dois primeiros anos do antigo 10 Grau sob a justificativa da necessidade de um tempo maior para a alfabetização das crianças oriundas de culturas não letradas. Não foi somente de um ato administrativo, significou, também, uma mudança de concepção sobre o processo de alfabetização.

Para subsidiar essa política foi implantado o Projeto Ipê. Uma ação formativa a distância, que buscou atingir toda a rede por meio da transmissão de programas de rádio e TV, acompanhados da discussão de textos de referência. Duran, Alves e Palma Filho (2005) avaliam que a iniciativa, embora alcançasse grandes contingentes em curto período, constituiu-se em um trabalho de superfície com a finalidade de divulgar ideias e propostas. Os programas focalizaram aspectos metodológicos da alfabetização na tentativa de combater o predomínio das cartilhas e das teorias da prontidão.

Ainda na gestão Franco Montoro teve início o debate acerca da construção de propostas curriculares que viessem a substituir os Guias Curriculares dos anos 1970. A CENP organizou ações para participação docente, promovendo debates entre professores, especialistas das universidades que assessoravam o órgão e representantes sindicais (PALMA FILHO, 2003).

A CENP, naquele momento, apostou no oferecimento de cursos de 30 horas em parceria com universidades públicas e privadas. Postura exatamente contrária ao processo de construção dos documentos, pois a divisão regional da formação e a falta de articulação entre as instituições participantes desencadeou no oferecimento de cursos, treinamentos e orientações técnicas pontuais. O tecnicismo educacional, impulsionado pelo modelo administrativo, influenciou fortemente os princípios da política formativa. A preocupação consistia em preparar o professor para planejar o ato educativo, seguindo ações de controle e avaliação. Fusari (1988, p. 172) explica que, à época, os princípios inspiradores das políticas 
paulistas de formação contínua eram similares aos promovidos por outras nove secretarias estaduais de educação, onde predominavam a:
a) ênfase no domínio de habilidade referente ao planejamento de ensino;
b) ênfase no conhecimento e utilização de novas tecnologias do ensino e recursos audiovisuais;
c) ênfase nas habilidades ligadas à avaliação da aprendizagem, daí a proliferação de treinamentos em métodos e técnicas de avaliação.

O autor identificou a ausência de ações sequenciadas e desarticulação entre planejamento, execução e avaliação, decorrentes da fragmentação e divisão dos órgãos responsáveis, mais preocupados com questões administrativas e burocráticas e não com os efeitos e propósitos da formação contínua. A não continuidade, aliada a uma abordagem técnica, no fundo, camuflava a falta de compromisso com a justiça social.

$\mathrm{Na}$ gestão seguinte, do governador Orestes Quércia (1987-1991), mudanças sucessivas na gestão da CENP desencadearam a pulverização de ações desconectadas. 0 órgão adotou uma política pragmática na definição dos conteúdos que comporiam a proposta curricular e, diante de uma participação reduzida de docentes, o trabalho foi concluído somente em 1992 (MARTINS, 1998).

Entre 1987 e 1991, além da continuidade do Ciclo Básico, foram implementados projetos que procuraram remediar os problemas de aprendizagem dos alunos, além da jornada única para docentes e discentes. No plano das ações de formação contínua nenhuma política consistente foi desenvolvida, apenas o oferecimento de cursos de capacitação estanques e desvinculados das necessidades e demandas das escolas. Os treinamentos propostos ignoravam a experiência dos professores da rede e desprezavam as condições objetivas de trabalho (FUSARI, 1988). Nas Delegacias ${ }^{1}$ de Ensino foram criadas as Oficinas Pedagógicas para concentrar as atividades formativas conduzidas por professores de diversas áreas de atuação que exerciam a função de Assistente Técnico-Pedagógico

\footnotetext{
${ }^{1}$ Denominação das atuais Diretorias de Ensino (DE).
} 
$(A T P)^{2}$, que se responsabilizavam pela multiplicação regional dos projetos gestados na CENP, o que fragmentou ainda mais o processo.

Durante o governo de Luiz Antonio Fleury Filho (1991-1995), a CENP, a FDE e o DRHU compartilharam a responsabilidade pelos programas formativos. A CENP ofereceu cursos de aperfeiçoamento para professores, por meio de convênios com universidades estaduais e instituições de notório reconhecimento. O Projeto Ipê foi retomado para oferecer materiais de suporte, visando a implementação da proposta curricular, bem como auxiliar na divulgação do Projeto Vídeo-escola, organizado pelas Fundações Roberto Marinho e Banco do Brasil. A FDE, que assumiu uma boa parte da formação de professores no período, promoveu cursos, seminários, encontros, oficinas, visitas técnicas e pesquisas. Já o DRHU, promoveu cursos e orientações técnicas de caráter pontual (UTSUMI, 1995).

A FDE criou os Centros de Aperfeiçoamento de Recursos Humanos (CARH). A oferta permanente de cursos extensivos e regulares, palestras, workshops e seminários buscava o aperfeiçoamento técnico dos profissionais da educação, além da difusão de pesquisas e estudos inovadores para resolução de problemas de ensino-aprendizagem dos alunos. Os centros compreendiam o Sistema Integrado de Multimeios, que dispunha de recursos tecnológicos para realização de cursos a distância, e o Banco de Projetos Educacionais, dedicado à documentação, análise e difusão de experiências pedagógicas inovadoras. A tentativa de sistematizar a oferta de ações formativas, segundo Utsumi (1995), não logrou o sucesso esperado devido à contingência de recursos financeiros.

Martins (1996) critica a ausência de uma política integrada para a formação contínua de professores no período, questionando a contribuição dos saberes adquiridos em cursos de 30 horas para a prática pedagógica, uma vez que, na maioria das vezes, limitaram-se a replicar conhecimentos acadêmicos embutidos em disciplinas de pós-graduação.

À época, a criação de Escolas-padrão ${ }^{3}$ oxigenou a política formativa. O magistério conquistou duas antigas reivindicações para a consolidação de um projeto pedagógico institucional: o Horário de Trabalho Pedagógico Coletivo (HTPC) ${ }^{4}$ e a função de professor-

\footnotetext{
${ }^{2}$ Denominação do atual Professor-coordenador de Oficina Pedagógica (PCOP).

${ }^{3}$ Unidades escolares que recebiam subsídios especiais da SEE/SP mediante o alcance de metas educacionais.

${ }^{4}$ Horário coletivo de professores destinado à formação, discussão dos projetos pedagógicos e resolução de problemas cotidianos da realidade escolar.
} 
coordenador, primeiramente, restrito às escolas-padrão e, mais tarde, presente em todas as unidades.

Marques (1997) e Cortina (2000) analisaram o programa de capacitação dos professores-coordenadores das Escolas-padrão, centrado na organização dos horários coletivos. Identificaram desarticulação e descontinuidade com relação às atividades conduzidas pelos órgãos centrais, ocasionadas por disputas políticas.

O projeto das Escolas-padrão já apresentava algumas das características da lógica neoliberal que se tornaria hegemônica. Em função do seu desempenho, um pequeno agrupamento de escolas estabeleceu contratos de gestão e recebeu verbas extraordinárias para o alcance das metas formuladas pela SEE/SP. Em princípio, trata-se de lógica semelhante àquela que fundamenta o bônus salarial nos anos 2000.

O estudo de Borges (2000) sobre a natureza da política formativa da rede estadual paulista entre 1986 e 1994 constatou que as medidas adotadas ampararam-se em questões técnicas, desconsiderando a cultura organizacional da escola e suas inter-relações com o meio social, político e comunitário. Souza (2006) analisou o período de 1982 a 1994 e verificou o fortalecimento do discurso da competência docente como marco regulador entre o fracasso e o sucesso no processo de ensino-aprendizagem. Segundo a autora, a política de formação buscou inculcar nos professores a ideia que o fraco desempenho dos alunos está vinculado à seleção e utilização de diferentes métodos e formas de ensino, ocultando os condicionantes objetivos da instituição escolar.

A educação tecnocrática, em vigor na rede estadual paulista nas décadas de 1980 e 1990, legitimou-se por intermédio de um discurso que concebia os professores como incapazes de desenvolver ações didático-pedagógicas atentas às demandas complexas de sua profissão. O que justificava a racionalização e controle do trabalho pedagógico, vistos como alternativa diante da incapacidade docente ou como instrumentos de vigilância do cumprimento de tarefas profissionais

Constata-se, no período, a adoção de políticas formativas de natureza vertical, com um viés tecnocrático e sem a participação dos professores no planejamento, execução ou avaliação. Apenas os conhecimentos produzidos fora da escola eram valorizados. Daí, a recorrência a agentes multiplicadores. Ou seja, um determinado grupo de profissionais, após uma etapa formativa, transmitiam os conteúdos aprendidos aos seus pares. Fusari (1988) 
apresenta ressalvas à ideia de multiplicadores, pois, nem todo educador que frequenta um curso tem condições de assumir sua reprodução no local de trabalho.

Concretamente, podemos afirmar que de 1983 a 1994 deram-se diversas tentativas de organização de uma política de formação contínua. Todavia, a descontinuidade e fragmentação dos projetos e ações impediram o estabelecimento de um projeto de longo prazo, algo desejável quando o foco é o desenvolvimento profissional (IMBERNÓN, 1994). O fato pode ser explicado por Fusari (1988), para quem as ações formativas são pautadas pelo imediatismo do tempo político-partidário, desconsiderando as necessidades $\mathrm{e}$ as preocupações concretas dos professores; e por Collares, Moysés e Geraldi (1999), quando denunciam os programas de formação contínua que atendem aos planos de governo e não a políticas assumidas pelos profissionais do ensino. A mudança administrativa significa um recomeçar do zero, negando-se a história.

Concluímos que a característica descontínua das políticas formativas da SEE/SP consolidou-se, tornando-se contínua, pois ao não apresentar momentos de ruptura, manteve inalteradas as relações de poder que perpassam todo o sistema estadual de ensino. Essa constatação fertiliza a suspeita de que a descontinuidade pode ser vista como um projeto de continuidade e manutenção dos interesses tecnocráticos.

\section{Ciclo II (1995-2006): o neoliberalismo bate à porta da formação}

A análise da produção acadêmica acerca da formação contínua de professores sinaliza uma importante mudança de paradigma teórico na segunda metade da última década do século XX (BRASIL, 2006). Entre 1990 e 1996, a racionalidade técnica foi operacionalizada por meio de programas de curta duração, em forma de treinamento. A partir de 1997, passa a vigorar o paradigma reflexivo, focado na relação complexa entre educação, universidade e sociedade do conhecimento.

$\mathrm{Na}$ rede estadual paulista deram-se mudanças paradigmáticas a partir da primeira gestão do governador Mário Covas (1995-2001). O processo de descentralização foi fortalecido, porém as justificativas de natureza democrática deram lugar à vertente gerencial. Substituíram-se conceitos como descentralização e participação popular por descentralização e produtividade, instaurando o período da eficiência pautada pela 
otimização dos recursos financeiros. A política educacional passou a ser vista como uma questão de gestão escolar, tendo em vista a economia de recursos (ADRIÃO, 2006).

A descentralização, efetivamente, tornou-se uma desconcentração de serviços administrativos. Anteriormente realizados pelos órgãos centrais, migraram para o interior da escola. Veja-se, por exemplo, a transformação das Associações de Pais e Mestres (APM) em instâncias jurídicas que passaram a receber verbas para execução de serviços essenciais, como manutenção dos prédios escolares e contratação de pessoal.

A SEE/SP lançou o programa $A$ escola de cara nova, um projeto modernizador da rede estadual, adequando-o às exigências da globalização econômica. Foram extintos órgãos intermediários e instituído o módulo de pessoal, que determinou a quantidade de servidores baseada no número de escolas atendidas. Essas ações reduziram o quadro de funcionários por meio da precarização do serviço público, visto que, na maioria dos casos, os módulos eram insuficientes para atender às demandas. Nas Oficinas Pedagógicas, os ATPs passaram a acompanhar a formação de todos os professores da DE que atuavam com o mesmo componente curricular. O enxugamento, entre 1995 e 1998, alcançou 864 escolas no Estado. A mágica foi possível graças ao aumento da relação professor/aluno e à implementação da correção de fluxo ${ }^{5}$ (ADRIÃO, 2006).

No campo das ações formativas, a CENP sofreu uma redução drástica do quadro de pessoal, vendo-se obrigada a terceirizar serviços via contratação de empresas e ONGs para o oferecimento de assessoria pedagógica, com especial destaque para o Centro de Estudos e Pesquisas em Educação, Cultura e Ação Comunitária (CENPEC). Para atender as exigências do Banco Mundial em função de empréstimos recebidos, a SEE/SP, entre janeiro de 1995 e dezembro de 1996, planejou o Programa de Educação Continuada (PEC) (CORTINA, 2000).

Implementado entre 1996 e 1998, o PEC combinou ações centralizadas e descentralizadas. Em nível centralizado, descreve Pompeu (2005), desenvolveram-se atividades com dirigentes e supervisores de ensino, diretores de escola, professorescoordenadores e assistentes técnico-pedagógicos, priorizando a liderança educacional. Em nível descentralizado, as ações formativas se dirigiram aos professores.

A SEE/SP sistematizou as prioridades das DEs e abriu espaço para que as universidades e demais agências interessadas apresentassem propostas de formação. As

\footnotetext{
${ }^{5}$ Projeto que visava acelerar o percurso curricular de maneira a diminuir a defasagem série/idade.
} 
instituições contratadas elaboraram e desenvolveram projetos com base nas demandas do polo sob sua responsabilidade. Isso possibilitou uma ampla diversidade de iniciativas, atendendo cerca de 90 mil servidores no período (GATTI, 2008). Cada DE escolheu, do rol de cursos contratados para sua região, aqueles que se aproximavam das necessidades identificadas pelas escolas. Apesar das tentativas de mapear as solicitações dos professores, num programa de capacitação dessa magnitude não há qualquer possibilidade de perguntar aos servidores quais são seus desejos, anseios e necessidades, muito menos, contemplá-los.

Ainda que limitado em alguns aspectos, Gatti (2008) apontou pontos positivos no PEC: a tentativa de atendimento de especificidades, a inserção do professor como sujeito ativo no processo e a utilização da metodologia da ação-reflexão durante as atividades formativas. Por outro lado, o PEC ajudou a introduzir nas escolas uma determinada concepção de educação, organizada a partir da pedagogia das competências. Consequentemente, as instituições contratadas restringiram o objetivo de suas ações ao saber fazer.

Na gestão Geraldo Alckmin (2001-2006) prevaleceu o oferecimento de cursos voltados para o atendimento de demandas da administração central, através de convênios com ONGs e universidades, por intermédio da CENP. Dentre as diversas ações formativas no período, as de maior relevância foram o Progestão, Teia do Saber, PEC - Formação Universitária, Ensino Médio em Rede, Bolsa Mestrado, Letra e Vida e Lien'chi.

O Progestão consistiu em um programa de formação continuada destinado aos gestores escolares, que intercalou atividades a distância e presenciais. O curso deu-se por iniciativa do Conselho Nacional de Secretários de Educação (CONSED), responsável pela produção dos materiais didáticos autoinstrucionais (impressos e vídeos). Em tese, o objetivo era formar líderes educacionais comprometidos com a construção de um projeto de gestão democrática, focada no sucesso escolar dos alunos das escolas públicas.

Por meio de convênios firmados com IES públicas e privadas, o programa Teia do Saber propunha-se a formar docentes do Ensino Fundamental e do Ensino Médio para utilização de metodologias arrojadas e práticas de avaliação como instrumento que possibilitasse o redirecionamento das ações, além de promover um ensino baseado no desenvolvimento de competências (SÃO PAULO, 2008b). Não por acaso, o edital exigia que 
os Parâmetros Curriculares Nacionais se constituíssem como referências dos projetos oferecidos, o que, efetivamente, denota uma restrição teórico-metodológica.

Princípios semelhantes inspiraram o PEC - Formação Universitária. Mediante um convênio com a PUC-SP, USP e UNESP, e visando atender aos ditames da legislação em vigor, os professores em atuação nos anos iniciais do Ensino Fundamental, que não eram portadores de diploma de Ensino Superior, foram estimulados a cursar uma Licenciatura especial que envolveu atividades presenciais e a distância (NICOLAU, 2006).

O Bolsa Mestrado ofereceu bolsas de estudo para professores que cursavam a pósgraduação stricto sensu. O programa compreendeu remuneração extra (muitas vezes, utilizada para pagar as mensalidades em instituições privadas) ou redução da jornada de trabalho sem prejuízos nos vencimentos. Em contrapartida, o professor deveria permanecer na rede por dois anos após o término dos estudos. A participação dependia da inserção autônoma no curso de pós-graduação, sendo possível, inclusive, realizar uma pesquisa de interesse pessoal desde que vinculada à educação ou à área de conhecimento específico do docente. A ausência de oportunidades para que os conhecimentos construídos no processo fossem revertidos para a própria rede revela o caráter individualista dessa política formativa. Em muitos casos, beneficiou apenas o participante, sem qualquer contribuição ao sistema público de ensino.

O programa de formação contínua Ensino Médio em Rede (EMR) foi concebido e coordenado pela CENP e gerenciado pela Fundação Vanzolini. Destinado aos ATPs, supervisores de ensino, professores-coordenadores e professores, contou com o financiamento do Programa de Melhoria e Expansão no Ensino Médio (PROMED/MEC) e do Banco Interamericano de Desenvolvimento (BID). Para sua efetivação, o EMR utilizou os ambientes virtuais de aprendizagem da Rede do Saber ${ }^{6}$ (teleconferências, videoconferências e ferramentas web), além de materiais de apoio especialmente desenvolvidos. A primeira fase, entre 2004 e 2005, voltou-se para a contextualização da proposta de formação e para a discussão das múltiplas representações dos atores envolvidos na prática educativa. Em 2006, o curso enfatizou o desenvolvimento curricular no Ensino Médio, tomando como base os Parâmetros Curriculares Nacionais do Ensino Médio.

\footnotetext{
${ }^{6}$ A Rede do Saber é um conjunto articulado de dispositivos tecnológicos para oferecer formação contínua à distância aos servidores da SEE/SP.
} 
O Letra e vida ${ }^{7}$ destinou-se aos professores alfabetizadores. Entre seus objetivos despontava a tentativa de mudança do paradigma da didática e das concepções de aprendizagem predominantes entre os educadores da rede estadual. A pretensão oficial era substituir o método fonético por uma abordagem baseada na concepção construtivista da aprendizagem.

Realizado em parceria com a Associação de Medicina Chinesa (AMC), o Lien Ch'i teve como finalidade capacitar os professores para ensinar a técnica corporal. Os idealizadores divulgavam que a proliferação da sua prática nas escolas estaduais traria benefícios metafísicos como tranquilidade, relaxamento, diminuição da agressividade, maior concentração, entre outros. Iniciado em 2003, o programa destinava-se aos professores de Educação Física e, mais tarde, a outros profissionais da educação.

As atividades relatadas evidenciam que, entre 1995 e 2006, a política de formação contínua da SEE/SP abrangeu cursos estanques, fragmentados e desarticulados, o que dificulta qualquer análise coletiva sobre a complexidade do contexto escolar. O que se pode aludir, no máximo, é a incorporação de conhecimentos descontextualizados pelos participantes ou a promoção de reflexões pessoais sobre a prática pedagógica. Como se a solução dos problemas enfrentados no cotidiano pudesse emanar dos indivíduos, ao invés de construir-se por meio do debate coletivo e democrático. A formação reflexiva centrada exclusivamente na própria prática desvia o foco dos obstáculos estruturais engendrados pelas desigualdades sociais, econômicas, políticas e culturais.

Contreras (2002) contesta as propostas de formação contínua que sugerem uma prática reflexiva. Ao questionar a reflexão como instrumento autossuficiente para uma prática educativa igualitária e libertadora, recorda que a noção de professor reflexivo legitima as reformas educacionais que responsabilizam o indivíduo pelo seu desempenho. Embora possa sugerir certa valorização do professor, a prática reflexiva suaviza o modelo instrumental técnico, sempre impositivo e impessoal.

É preciso ter em mente que "o ensino, enquanto prática social, não é definido ex novo pelos docentes, mas estes se incorporam a uma instituição, a qual já responde a certas pretensões, uma história, rotinas e estilos preestabelecidos" (CONTRERAS, 2002, p. 149).

\footnotetext{
${ }^{7}$ O material desse programa de formação foi produzido a partir do Programa de Formação de Professores Alfabetizadores organizado pelo MEC.
} 
Daí, a desconfiança de que ações individuais possam resolver os problemas estruturais da educação escolar. Restringir a reflexão aos limites da sala de aula enfraquece a ação política e social do professor, impedindo-o de pensar sobre as verdadeiras causas do fracasso escolar e de atuar nas instâncias maiores de decisão e intervenção. Uma política de formação reflexiva contribui para fortalecer ideias conservadoras que imputam aos docentes a responsabilidade total pelos problemas estruturais do ensino. Isso não significa descartar a necessidade dos professores refletirem e analisarem suas práticas, nem tampouco eximi-los da responsabilidade que lhes é inerente.

No período analisado, sob o paradigma do desenvolvimento de competências, foram implementadas medidas neoliberais como bonificação salarial conforme a média obtida pela escola nas avaliações padronizadas, além da determinação central de conteúdos curriculares. Em termos oficiais, verificou-se a disseminação de uma política educacional que acenava, claramente, para a atuação no mercado, e desqualificava o trabalho desenvolvido pelo professorado.

Ora, a escola possui uma tarefa eminentemente social, de modo consequente, a superação dos seus problemas exige um esforço coletivo. Com base nesse raciocínio, é possível traçar fortes questionamentos às políticas de formação contínua da rede estadual paulista, no período compreendido entre 1995 e 2006. Focadas exclusivamente no desenvolvimento de competências docentes, passaram ao largo da instituição educativa. Uma vez que os problemas educacionais não se resolveram, é de se esperar que os professores, que tantas vezes foram expostos ao pensamento hegemônico, terminem por ceder, pois aprenderam que são incapazes de, coletivamente, encontrar alternativas para contornar as dificuldades cotidianas.

\section{Considerações finais}

Apesar das críticas às políticas de formação contínua implementadas pela SEE/SP nas três últimas décadas, reconhecemos que os pressupostos adotados se alinham às concepções hegemônicas presentes nas redes de ensino brasileiras. Nunes (2000), por exemplo, denuncia a ausência, na história brasileira, de experiências e proposições de uma política educacional sistemática de longo prazo para a formação de professores. Analisando a esfera federal, observa que os programas são desarticulados, de caráter assistencial, 
notoriamente emergencial, nitidamente provisórios e definidos conforme os interesses de grupos político-partidários ou empresariais.

Nossas análises apontam na mesma direção do estudo de Souza (2005), que identificou uma íntima relação entre as políticas de formação contínua e os pressupostos ideológicos dos partidos políticos que ocuparam a administração pública municipal paulistana. Partidos conservadores adotam, geralmente, programas pragmáticos e fechados de formação contínua, enquanto nos governos progressistas prevalecem ações formativas que privilegiavam a democracia, o diálogo, a constituição de grupos de discussão permanentes e estáveis.

A análise empreendida também se aproxima das posições de Gatti (2003), quando sinaliza certa consonância entre mentores e implementadores das práticas formativas. Revestida do ideário tecnocrata, a educação continuada é um momento de oferecimento de informações, conteúdos e modelos focados na racionalidade dos professores, pois se espera que a partir do domínio de novos conhecimentos haverá mudanças nas posturas e formas de agir.

Trata-se de uma concepção limitada, pois os professores interagem com grupos e acumulam experiências que veiculam distintas visões de educação e modos de ser, configurando representações e valores que filtram aquilo que Ihes chega. Dessa forma, os conhecimentos adquirem ou não sentido; são incorporados ou não, em função de uma complexidade de relações não apenas cognitivas, mas, sociais e culturais. Por isso, ações formativas que valorizam, exclusivamente, os aspectos individuais, muitas vezes, esbarram nas representações e na cultura experiencial dos docentes. "Essa é uma das razões pelas quais tantos programas que visam a mudanças cognitivas, de práticas, de posturas, mostram-se ineficazes" (GATTI, 2003, p. 192).

O estudo empreendido permite afirmar que a concepção formativa da rede estadual paulista é resultado de um processo de lutas simbólicas, no qual diversos grupos sociais atuaram para fazer prevalecer seus valores e concepções. Em cada período, as relações de poder produziram ações formativas em pleno acordo com as demandas do momento político, histórico e econômico.

No primeiro ciclo, fortemente influenciado pelo debate democrático, as políticas mostraram-se rarefeitas e descontínuas, o que dificultou a consecução de ações que 
poderiam interferir na formação de professores engajados com a melhoria do processo de ensino-aprendizagem e com a construção de currículos democráticos. No segundo ciclo, marcado pelo ideário econômico, as iniciativas foram permeadas pela racionalização dos recursos, potencializada pelo discurso fazer mais por menos, e pelo foco no mercado de trabalho. Privilegiou-se o caráter técnico, valorizando-se a transposição de conhecimentos produzidos fora da escola.

Após as análises, é possível inferir que no espaço de tempo analisado a política formativa da SEE/SP distanciou-se dos princípios de democracia, justiça social e participação popular. Nesse quadro, ganham relevância todas as lutas para empreender políticas formativas que considerem os professores como sujeitos participantes do processo. Isso feito, teremos dado o primeiro passo para consolidação de uma formação docente convergente com a construção coletiva dos projetos pedagógicos das escolas.

\section{Referências}

ADRIÃO, T. Educação e produtividade: a reforma do ensino paulista e a desobrigação do Estado. São Paulo: Xamã, 2006.

BORGES, A. S. Análise da formação continuada dos professores da rede pública de ensino do Estado de São Paulo. In: MARIN, A. J. (Org.). Educação Continuada. Campinas: Papirus, 2000.

BRASIL. Ministério da Educação. Formação de profissionais da educação (1997-2002). Brasília: MEC/INEP, 2006.

COLLARES, C. A. L.; MOYSÉS, M. A. A.; GERALDI, J. W. Educação Continuada: a política de descontinuidade. Educação \& Sociedade, Campinas, v. 17, ano XX, n. 68, p. 202-219, dez. 1999.

CONTRERAS, J. A autonomia de professores. São Paulo: Cortez, 2002.

CORTINA, R. L. Política Educacional Paulista no Governo Covas (1995-1998): uma avaliação política sob a perspectiva da modernização. 2000. 331f. Tese (Doutorado em Educação) Universidade de São Paulo/FEUSP, São Paulo, 2000. 
DURAN, M. C. G; ALVES, M. L.; PALMA FILHO, J. C. Vinte anos da política do ciclo básico na rede estadual paulista. Cadernos de Pesquisa, São Paulo, v. 35, n. 124, p. 83-112, abr. 2005.

FUSARI, J. C. A educação do educador em serviço: o treinamento de professores em questão. 1988. 250f. Dissertação (Mestrado em Educação) - Pontifícia Universidade Católica/PUCSP, São Paulo, 1988.

GATTI, B. A. Análise das políticas públicas para formação continuada no Brasil, na última década. Rev. Bras. Educ., Rio de Janeiro, v. 13, n. 37, p. 57-70, jan./abr. 2008.

GATTI, B. A. Formação contínua de professores: a questão psicossocial. Cadernos de Pesquisa, São Paulo, v. 01, n. 119, p. 191-204, jul. 2003.

IMBERNÓN, F. La formación y el desarrollo profesional del profesorado: hacia una nueva cultura profesional. Barcelona: Grão, 1994.

MARQUES, W. Escola-padrão: acertos e equívocos de uma política educacional. 1997. $227 f$. Tese (Doutorado em Educação) - Universidade de Campinas/FEUNICAMP, Campinas, 1997.

MARTINS, M. C. A CENP e a criação do currículo de História: a descontinuidade de um projeto educacional. Revista Brasileira de História, São Paulo, v.18, n.36, p.39-60, jul/dez. 1998.

MARTINS, A. M. Formação contínua de professores: parceria universidade - rede estadual de ensino. Revista FEUSP, São Paulo. vol. 22, n.2, p.189-205, jul/dez. 1996.

NICOLAU, M. L. M. As marcas que o PEC - Formação Universitária - deixou à Coordenação da USP. IN: NICOLAU, M. L. M.; KRASILCHIK, M. (Org.). Uma experiência de formação de professores na USP - PEC. São Paulo: Imprensa Oficial, 2006, p. 07-20.

NUNES, C. S. C. Os sentidos da formação contínua de professores: o mundo do trabalho e a formação de professores no Brasil. 2000. 152f. Tese (Doutorado em Educação) Universidade de Campinas /FEUNICAMP, Campinas, 2000.

PALMA FILHO, J. C. Reorganização do Ensino Fundamental na rede estadual de ensino paulista. Política e ideologia: memórias. IN: PALMA FILHO, J. C.; ALVES, M. L.; DURAN, M. C. 
G. (Orgs.) Ciclo Básico em São Paulo: Memórias da educação nos anos 1980. São Paulo: Xamã, 2003. p. 17-57.

POMPEU, C. A. História, políticas e projetos: formação contínua de professores de história (ESTADO DE SÃO PAULO - PEC 1996-1998). 2005. 123f. Dissertação (Mestrado em Educação) - Universidade de Campinas /FEUNICAMP, Campinas, 2005.

SÃO PAULO (ESTADO). Atribuições da Coordenadoria de Estudos e Normas Pedagógicas. Disponível em http://cenp.edunet.sp.gov.br. Acesso em: 20 nov. 2008 .

SÃO PAULO (ESTADO). Projeto Básico - Teia do Saber 2007. Disponível em http://cenp.edunet.sp.gov.br/forcont2007/arquivos/Projeto\%20Basico_nova_versao.pdf. Acesso em: 15 ago. 2008b.

SOUZA, D. T. R. Formação continuada de professores e fracasso escolar: problematizando o argumento da incompetência. Educação e Pesquisa, São Paulo, v.32, n.3, p.477-492, set./dez. 2006.

SOUZA, V. M. Formação em serviço de professores da Secretaria Municipal de Educação de São Paulo (1956-2004): Gênese, transformações e desafios. 2005. 237f. Tese (Doutorado em Educação) - Universidade de São Paulo/FEUSP, São Paulo, 2005.

UTSUMI, M. C. Escola-padrão: Avanço na melhoria do ensino? 1995. 193f. Dissertação (Mestrado em Educação) - Universidade de Campinas /FEUNICAMP, Campinas 1995. 